\title{
The Outflow Tract of the Left Ventricle
}

\author{
ROBERT WALMSLEY AND HAMISH WATSON
}

From the Department of Anatomy, St. Salvator's College, St. Andrews, and the Department of Medicine, Queen's College in the University of St. Andrews, Dundee

Intensive study of the infundibulum in congenital and acquired lesions has led to a much better appreciation of the anatomy and function of the right ventricular outflow tract in health and disease. The rapidly spreading practice of replacing severely damaged aortic and mitral valves, together with current interest in subaortic stenosis (Braunwald et al., 1964) have focused attention on the outflow tract of the left ventricle, which is more complex and less well understood than its opposite number on the right side of the heart. The object of this paper is to describe the anatomy of the left ventricular outflow tract, to illustrate its relation to other cardiac structures, and to emphasize the basic importance of the fibrous skeleton of the human heart.

The cavity of each ventricle has a region that is concerned mainly with the inflow of blood from the corresponding atrium and one that is associated with the outflow of blood into either the pulmonary trunk or the ascending aorta. These two parts are now customarily designated the "inflow" and "outflow" tracts of the right and left ventricles. The outflow tracts lie above and in front of the inflow tracts and the walls of their terminal parts tend to be smoother than those of the inflow tracts, which are characterized by the raised muscular ridges of the trabeculæ carneæ.

\section{SUBAORTIC REgION}

The outflow tract of the left ventricle extends upwards from the apex of the chamber to the aortic valve and many names have recently been used to designate its uppermost or terminal part, namely subaortic (Braunwald et al., 1960), subvalvar (Brock, 1957), subvalvular (Kirklin and Ellis, 1961), and vestibule (Luisada, 1961). While we fully appreciate that the term vestibule is seldom used at present by clinicians when describing lesions in this region of the heart, we have chosen to use the term aortic vestibule in this communication, because it is Received August 9, 1965.

2F the term used in standard anatomical texts, including Gray's Anatomy (1962) and Cunningham's Textbook of Anatomy (1964).

In transverse sections made through the chest about the level of the fourth costal cartilages (Fig. 1), it is possible to demonstrate the relative positions of all four chambers of the heart. In such sections the interventricular and interatrial septa are seen to be "in line" with each other and placed at an angle of approximately $45^{\circ}$ to the median plane. We consider that it is necessary to appreciate this obliquity of the septa separating the atria and the ventricles in order to understand the clinical anatomy of the heart, since it determines that the right heart lies equally as much in front of the left heart as it does alongside it.

The right and the left hearts differ considerably in the relationship that their inflow and outflow tracts have to each other. In the right ventricle the inflow and outflow tracts lie parallel to the interventricular septum and it is therefore a simple matter, as can be seen in Fig. 2, to prepare an oblique vertical section that demonstrates the greater part of the right heart. Within the left heart, on the other hand, the blood pursues an entirely different course and direction in its passage from the inflow to the outflow tract of the ventricle. This becomes immediately apparent when it is appreciated that the antero-medial wall of the vestibule or subaortic region is formed by the interventricular septum and the postero-lateral wall by the aortic cusp of the mitral valve. In order to simplify the terminology adopted in this communication, the boundaries of the left ventricular outflow tract will be referred to simply as its anterior and posterior walls. Because the relation between the inflow and outflow tracts of the left ventricle is different from those of the right, a section parallel to the one in Fig. 2, again made parallel to the interventricular septum and passing through the middle of the left atrium, contains only the trabeculated inflow portion of 


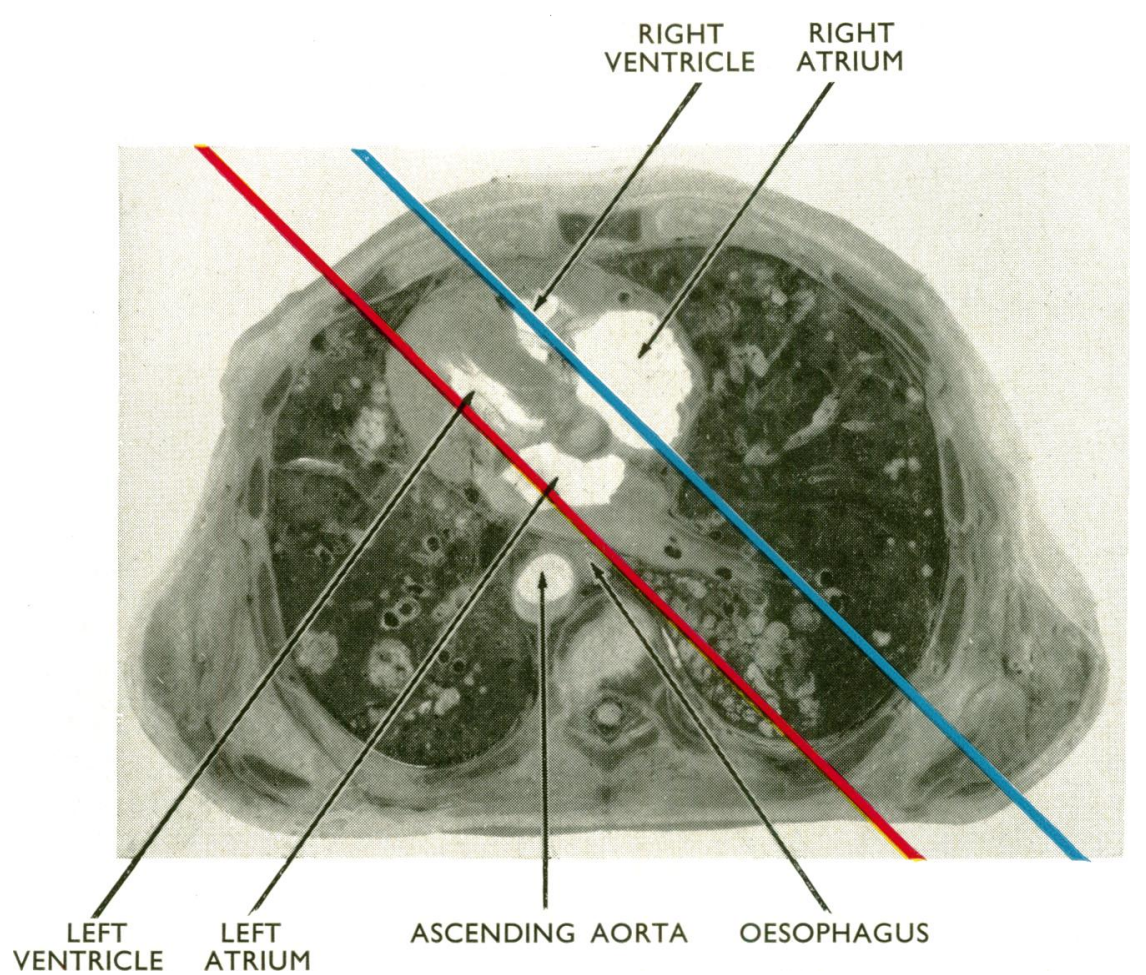

FIg. 1.-Transverse section of adult thorax at the level of the 4th costal cartilages. The section shows all four chambers of the heart, and it will be noted that the interatrial septum is in line with the right face of the interventricular septum. In this specimen a small part of the ascending aorta intervenes between the interatrial and interventricular septa. The septa lie at an angle of approximately $45^{\circ}$ to the median plane and the right heart therefore lies as much in front of the left heart as it does to its right side. The direction of the flow of blood in the right and left hearts is indicated by red and blue lines. In each case it will be noted that the blood in its passage from the atrium to the corresponding ventricle passes forwards and to the left at an angle of approximately $45^{\circ}$. (Unstained mounted section. $\times 0.33$.)

the left ventricle and none of its smoother-walled outflow tract (Fig. 3). More than 130 years ago, Dr. John Reid, later Professor of Anatomy in St. Andrews University, described, in Todd's Cyclopedia of Anatomy and Physiology (1839), how the aortic opening lies in the upper right corner of the left ventricle and is placed both to the right and also anterior to the mitral orifice. It has accordingly been found that if a vertical section through the heart is made in such a manner that it cuts approximately through the orifices of both the right and left coronary arteries, then it will also demonstrate both the inflow and outflow tracts of the left ventricle. Such a section through the left ventricle is shown in Fig. 4, and it demonstrates the key position that the aortic cusp of the mitral valve has in the left ventricle, and that it virtually divides the chamber into its inflow and outflow parts. The blood in its course from the left atrium into the inflow tract of the left ventricle first flows forwards and to the left upon the atrial face of the aortic cusp of the mitral valve towards the apex; it then turns round the free border of the cusp, and in doing so it passes upwards and to the right over its ventricular face, which forms the posterior wall of the vestibule, and thence through the aortic valve. During its course within the left ventricle the blood has, therefore, a complicated course. It is of interest that certain prosthetic valves in current use take advantage of the fact that the aortic cusp of the mitral valve has been removed and by opening eccentrically eject blood from the left atrium directly into the aortic vestibule. The ventricular outflow course of the blood is upwards and to the right with an angulation of about $90^{\circ}$ to the inflow tract, and it is for this reason that a section that passes parallel to the interventricular septum cannot demonstrate both the inflow and outflow tracts of the left ventricle, whereas in the right heart, a section in the same plane shows both tracts. 


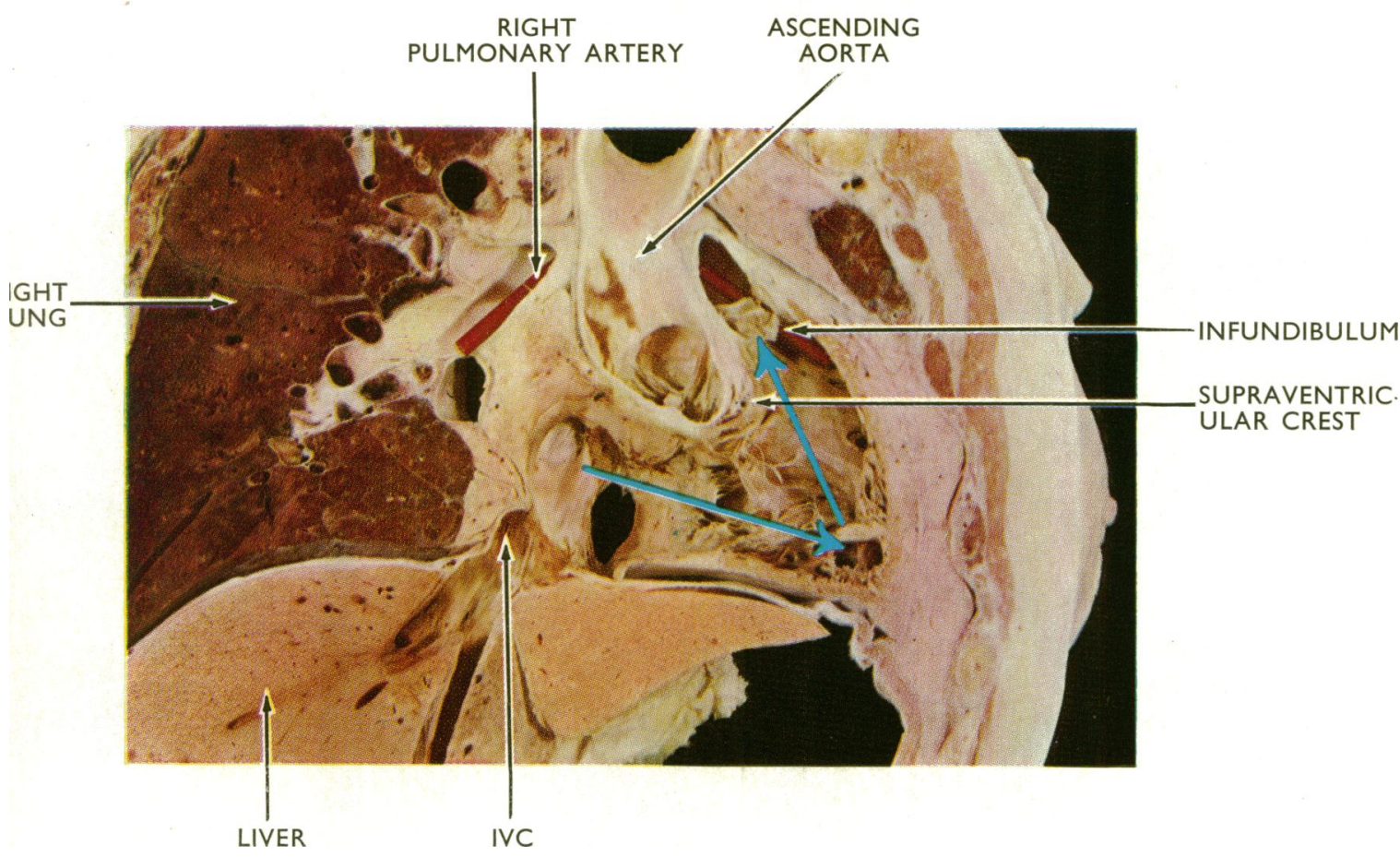

FIG. 2.-Vertical section through the right heart as viewed from the right side. The inferior vena cava is seen to pass through the diaphragm obliquely in order to enter the right atrium, but the section has failed to pass through the superior cava. The inflow and the outflow tracts of the right ventricle are indicated by blue arrows and the cavity of the right ventricle has a characteristic U-shaped form. The supraventricular crest is fairly prominent and helps to bound the infundibulum (conus arteriosus) posteriorly. The smoothness of the infundibular wall is apparent in this section. It will be noted that the outflow tract of the right ventricle lies both above and in front of the inflow tract, and in turn that part of the outflow tract represented by the infundibulum lies anterior to the ascending aorta. (Unstained mounted section. $\times 0.5$.)

\section{CARdiac Skeleton}

In order to appreciate fully the intimate relationship that exists between the aortic and mitral valves, it is necessary to give further consideration to the cardiac skeleton. This is a mass of fibrous tissue that surrounds and separates the valve orifices from which the valve cusps arise. The fibrous skeleton is illustrated diagrammatically in Fig. 5 and in it an attempt is made to indicate the common fibrous origin of the contiguous parts of the two posterior cusps of the aortic valve and the aortic cusp of the mitral valve to the skeleton. At the rightmost part of this common origin there is an expansion of the fibrous tissue which forms a mass termed the right fibrous trigone. It is within the right fibrous trigone that the well-known os cordis forms in both the ox and the sheep, and it is on account of the continuity which this trigone has with the membranous part of the interventricular septum (Fig. 5) that the os cordis reaches downwards into the upper part of the membranous septum.
Likewise other parts of the cardiac skeleton show considerable differences in their structure in different animals and also at different ages. In the horse, for example, true cartilage is a common component of the right fibrous trigone, and there is frequently a similar mass of cartilage in the left trigone, which is at the left end of that part of the cardiac skeleton which lies between the left posterior aortic cusp and the aortic cusp of the mitral valve (Walmsley, 1929). So too, in the pig, cartilages are frequently found in these regions, and phylogenetically the structure of this part of the cardiac skeleton appears to be relatively unstable.

In the human heart the proximity between the posterior cusps of the aortic valve and the anterior or aortic cusp of the mitral valve can be equally well demonstrated in prenatal and postnatal hearts of all ages. In our collection of specimens, however, it is best shown in thin sections of full-term foetal hearts (Fig. 6) where the bases of the posterior aortic cusps are seen to be intimately related to 
the base of the mitral cusp of the aortic valve. The contiguity of these structures at their attachment to the fibrous skeleton of the heart explains the frequency with which both valves are involved concurrently in disease processes. When sections of this part of the fibrous cardiac skeleton are examined, it can readily be appreciated that a functional upset, such as occurs when a myocardial infarct involving the associated papillary muscle results in detachment of the chordx tendinex, or gross structural damage to either valve, such as occurs in rheumatic heart disease, will have a profound hæmodynamic effect upon the whole left heart. The very nature of this area, in which so many important structures adjoin and lie alongside each other, emphasizes the technical problems involved in the surgery of valve replacement, both at the time of operation and in obtaining a satisfactory long-term result.

\section{Posterior Wall of Aortic Vestibule}

Though the posterior wall of the aortic vestibule has a truly postero-lateral relationship to the upper part of the outflow tract of the left ventricle, for the sake of simplicity it has been considered appropriate to refer to it simply as the "posterior wall". A major feature of the aortic cusp of the mitral valve is that it does not limit its attachment to its base but is also attached on its medial and lateral sides (Fig. 7). On the medial (or septal) side, it is attached near the junction of the interatrial septum and the membranous part of the interventricular 


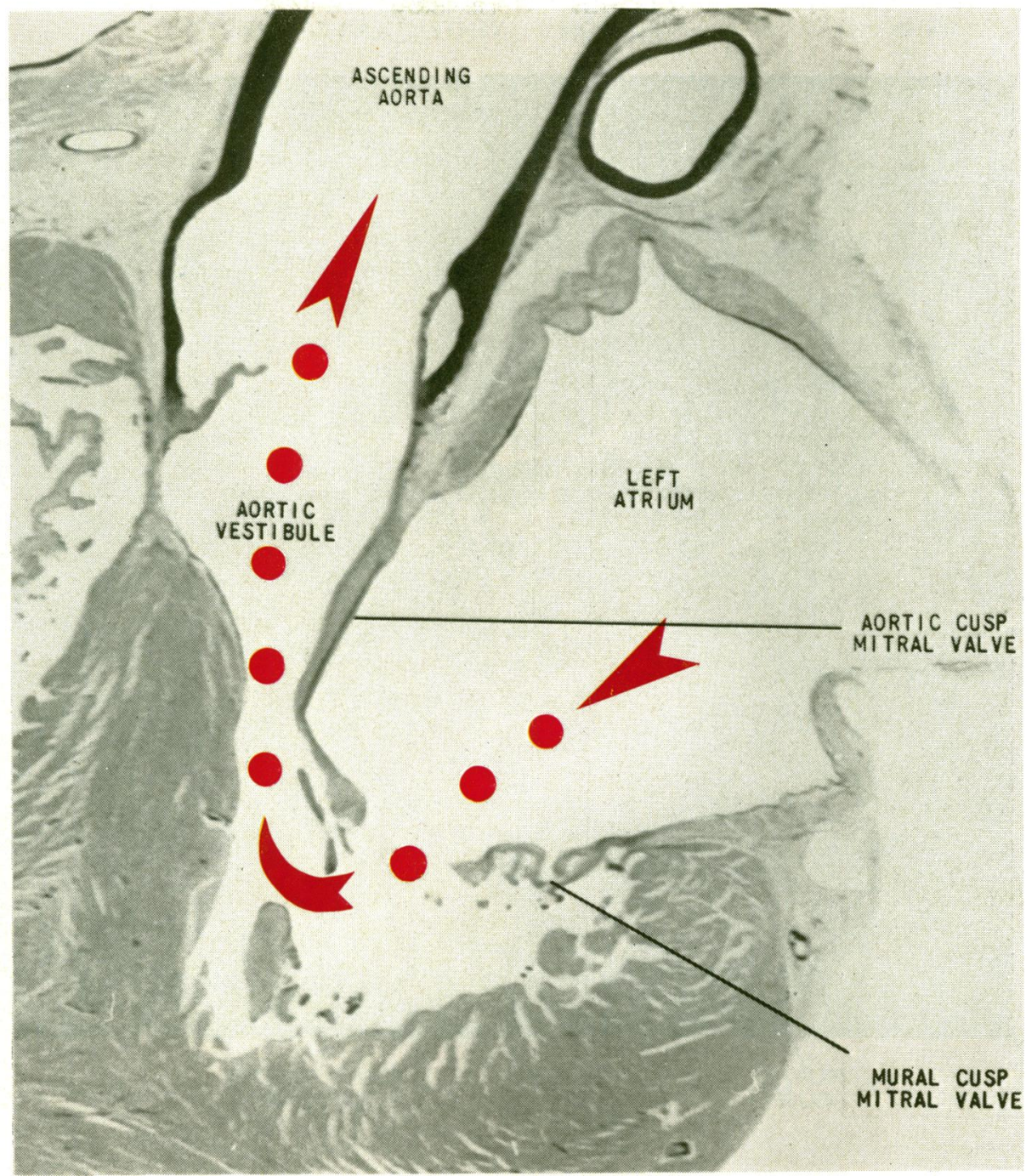

Fig. 4.-Oblique vertical section of left heart to illustrate both the inflow and outflow tracts of the left ventricle. The course of the blood in passing from the left atrium into the vestibule and ascending aorta is indicated by red dots and arrows. It will be noted that the aortic cusp of the mitral valve separates the inflow and outflow tracts of this ventricle, and furthermore that the aortic cusp forms the posterior wall of the vestibule wherreas the anterior wall is formed by the interventricular septum. (Orcein stain for elastic tissue. $\times 3$.)

septum, whereas on the lateral (or mural) side its attachment is in the region of the coronary (atrioventricular) sulcus (Fig. 7). It is also noticeable that the cusp is thicker in its medial than in its lateral part, and that the medial and lateral attachments extend downwards from the cardiac skeleton for approximately $1 \mathrm{~cm}$., thus forming with the interventricular septum a true fibromuscular canal, whose posterior wall is entirely membranous.
In the lower part of the vestibule, the site of fusion of the smooth-walled aortic cusp and the ridged mural cusp of the mitral valve is readily apparent (Fig. 8a), and further evidence of the difference in form of the two cusps is seen when a section is made below the line of fusion of the cusps and where they are seen to exist as separate entities (Fig. 8b). The fact that in health the cusps of the mitral valve are fused together in this way for a short 
distance below the annulus is a point of some practical importance and should be taken into account when setting the width of mechanical dilators for the surgical relief of mitral stenosis; it may well be that some cases of traumatic mitral incompetence are due to over-zealous splitting of fused commissures with the consequent tearing apart of elements that are normally fused.

\section{ANTERIOR WALI OF AORTIC Vestibule}

The anterior wall of the aortic vestibule is formed partly by the membranous and partly by the muscular parts of the interventricular septum. The upper part of the membranous interventricular septum is directly continuous with the right wall of the ascending aorta (Fig. 9a), and it is only a short distance below the right posterior aortic cusp that 


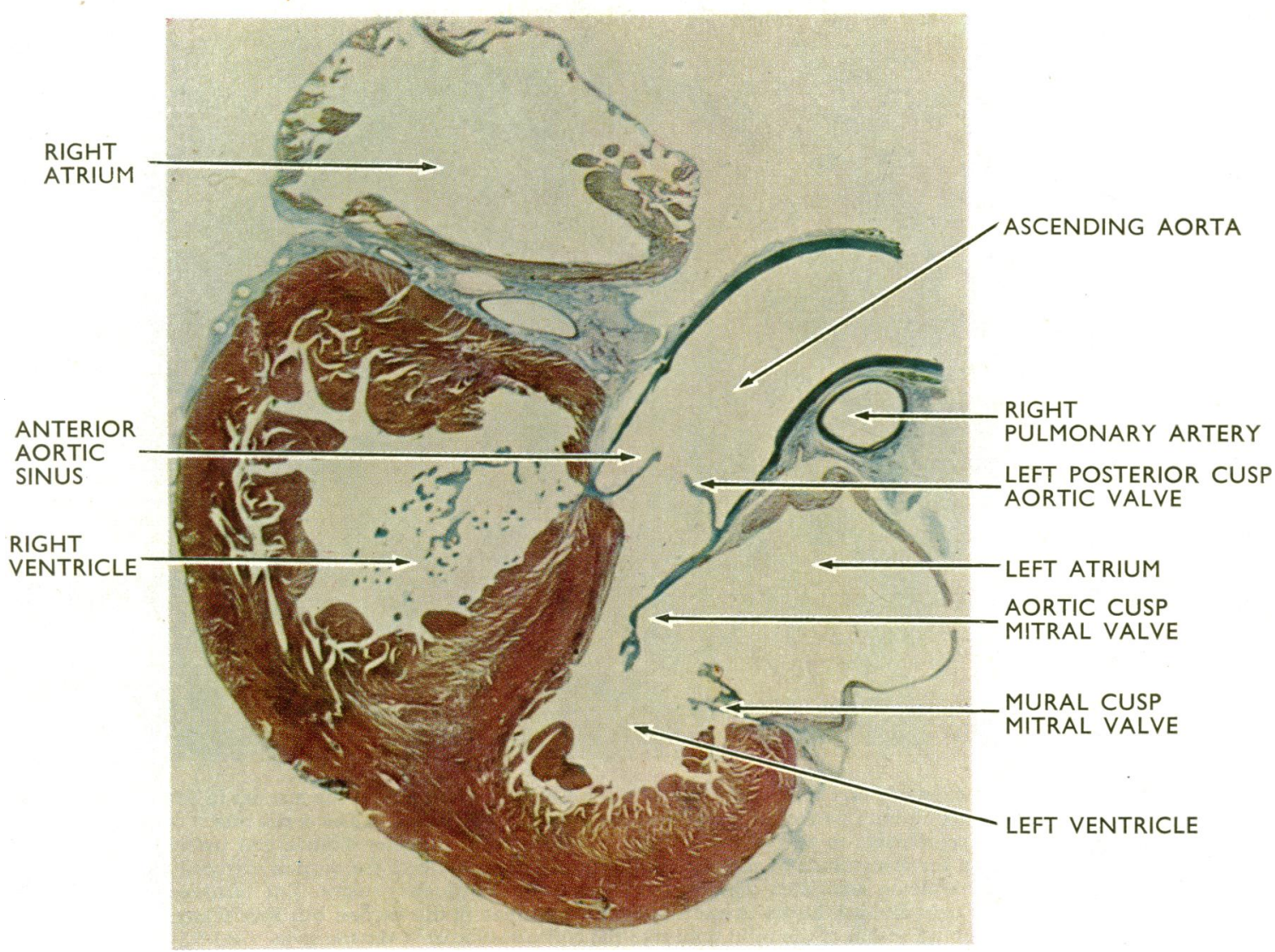

FIG. 6.-Section through heart of a full-term human foetus. The section has passed through the heart near the origins of the right and the left coronary arteries. Sections cut in this plane demonstrate the manner in which the aortic cusp of the mitral valve and the posterior cusps of the aortic valve have a common attachment to the cardiac skeleton. It will also be noted that the anterior aortic sinus is defined at its upper end by a well-defined ridge on the ascending aorta. The distinctness of these ridges at the upper margins of the aortic sinuses varies considerably. (Masson stain. $\times 3$.)

the medial wall of the right atrium gains attachment to the membranous septum. The membranous part of the interventricular septum is an integral part of the cardiac skeleton (Fig. 5), and it is consistent with this morphological feature that the muscular fibres of the right atrium are attached to it. The right posterior (non-coronary) cusp of the aortic valve, which is the lowest in position of the three aortic cusps, is also seen in Fig. 9a and 9b, and it is invariably attached to the membranous septum precisely at its junction with the ascending aorta. These sections, too, indicate the manner in which a defect may be present in the tetralogy of Fallot complex, when the continuity between the lower end of the aorta and the membranous part of the interventricular septum is interrupted and a varying degree of overriding takes place. It can be readily appreciated how in such an anatomical lesion the right ventricle will eject part of its content directly through the vestibule into the systemic circulation.

The septal cusp of the tricuspid valve bears a variable relation to the two parts of the interventricular septum, as in some places it is attached to the endocardium covering the muscular part of the septum (Fig. 9a), whereas in other regions it is attached directly to the membranous part of the septum (Fig. 9b) at a variable distance from the muscle. The ventricular surface of the septal cusp is characterized by numerous and irregularly situated chordæ tendinex: these chordæ arise from the uppermost part of the interventricular septum and bridge the gap between the cusp and the septum. In some animals the short chordæ of the third order are fused to form a membrana chordarum. In 


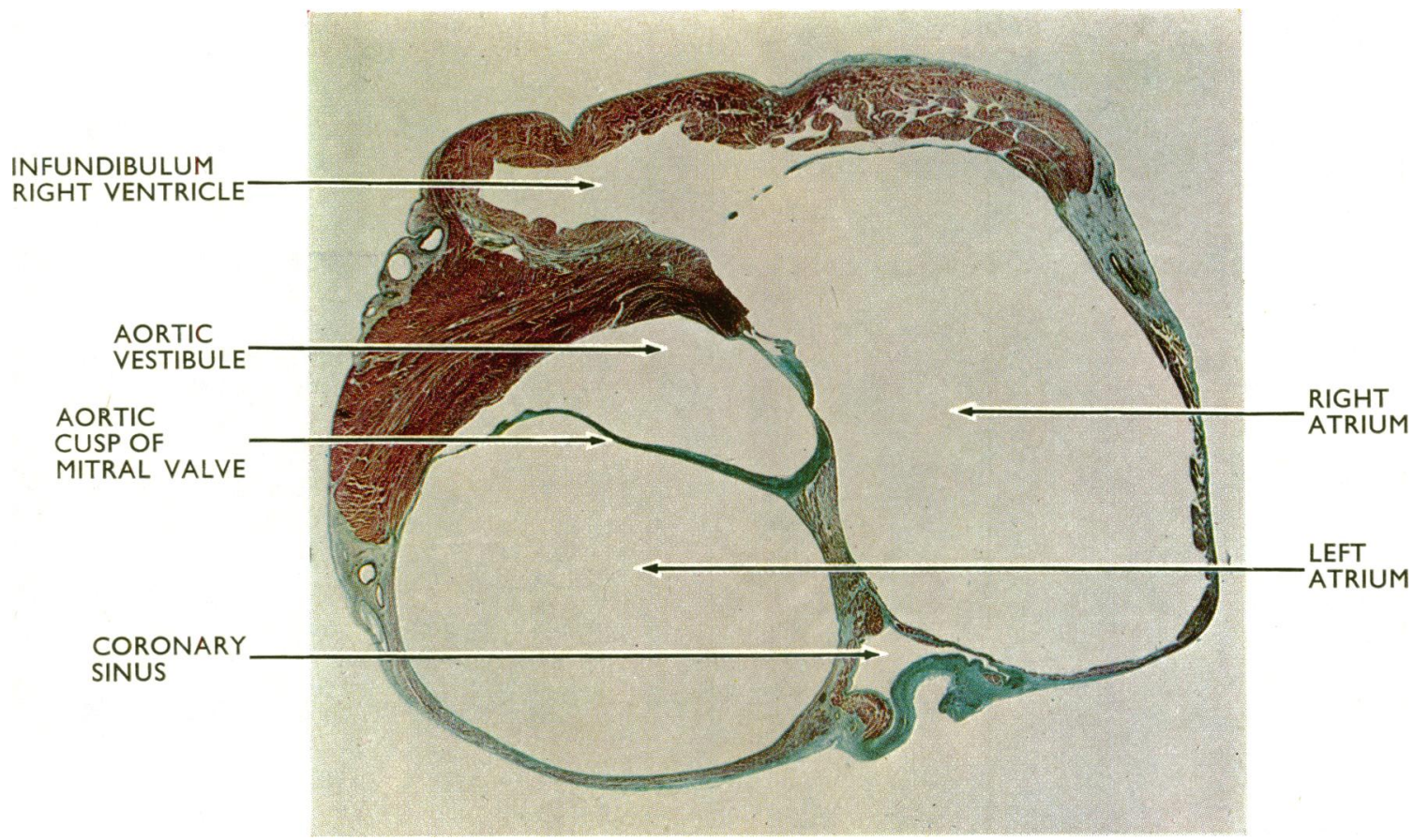

FIG. 7.-Oblique section of heart of 15 -year-old boy. This section demonstrates the manner in which the aortic cusp is attached on both its medial (septal) and its lateral (mural) sides. The aortic mitral cusp has assumed a position comparable to that which it must adopt during ventricular diastole and separates the left atrium from the aortic vestibule of the left ventricle. At its lateral end the cusp is attached to that part of the cardiac skeleton associated with the coronary (atrio-ventricular) sulcus. The relationships of various parts of the right and left hearts to one another are apparent in this section but special attention is drawn to the relationship of the right atrium to the aortic vestibule. (Masson stain. $\times 1 \cdot 5$.)

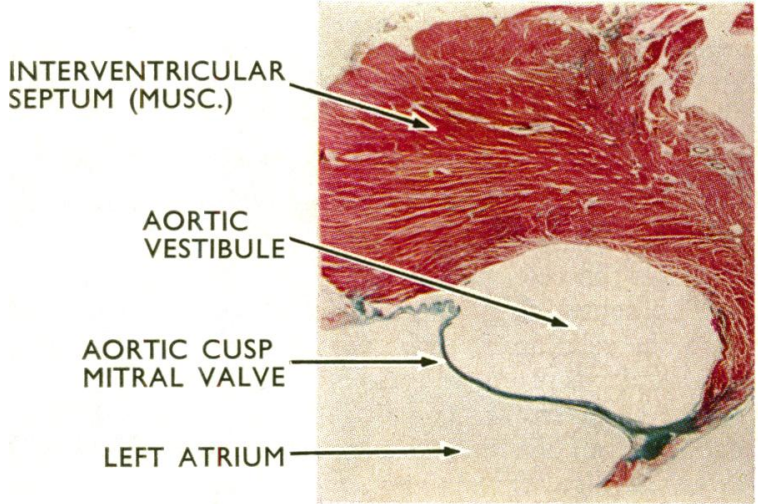

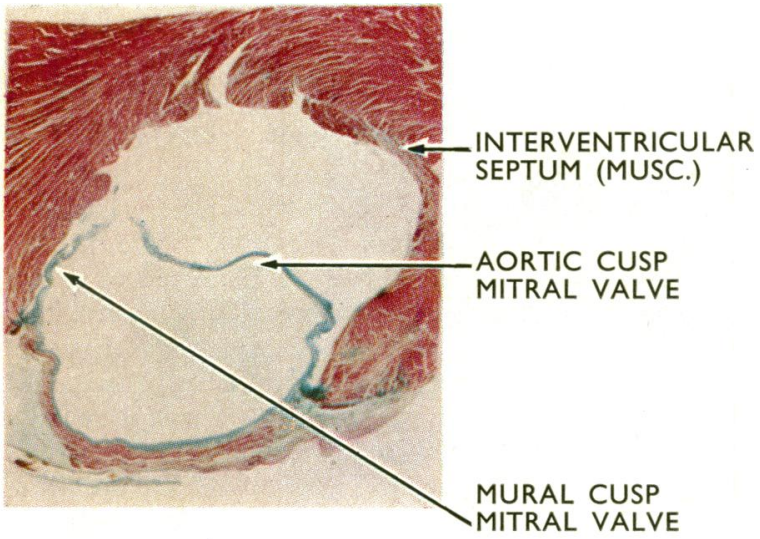

b

FIg. 8a.-Transverse section through the lower part of the aortic vestibule in an adult human heart. The lower part of the posterior wall of the vestibule is formed by the fusion of the aortic and mural cusps of the mitral valve, and it is consistent with their form that the aortic cusp is smooth whereas the mural cusp is ridged by the chordæ tendinex. (Masson stain. $\times 1 \cdot 2$.)

Fig. 8b.-This section is from the same heart as Fig. 8a, but is at a slightly lower level. It is below the level of the fusion of the aortic and mural cusps of the mitral valve, and these are seen as distinct elements.

(Masson stain. $\times 1 \cdot 2$.) 


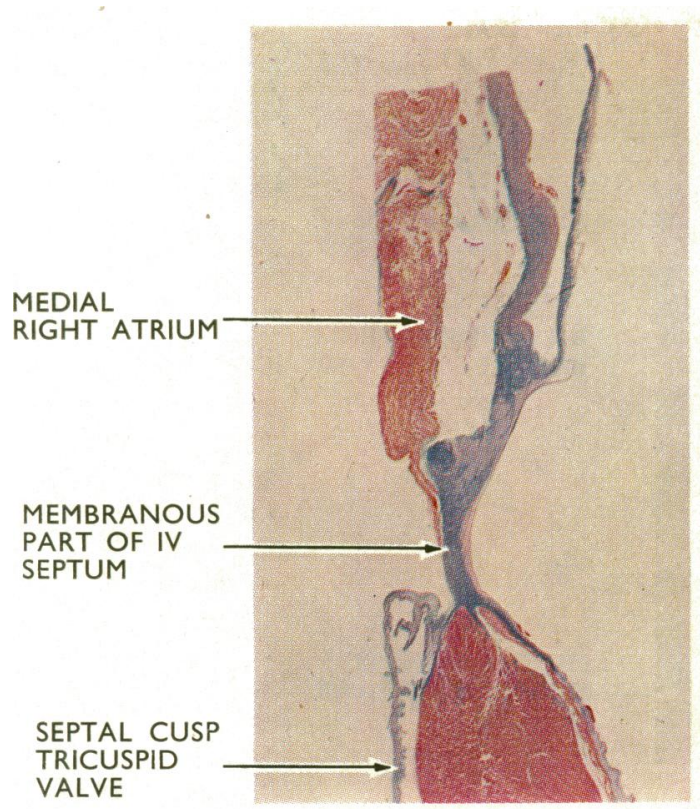

a

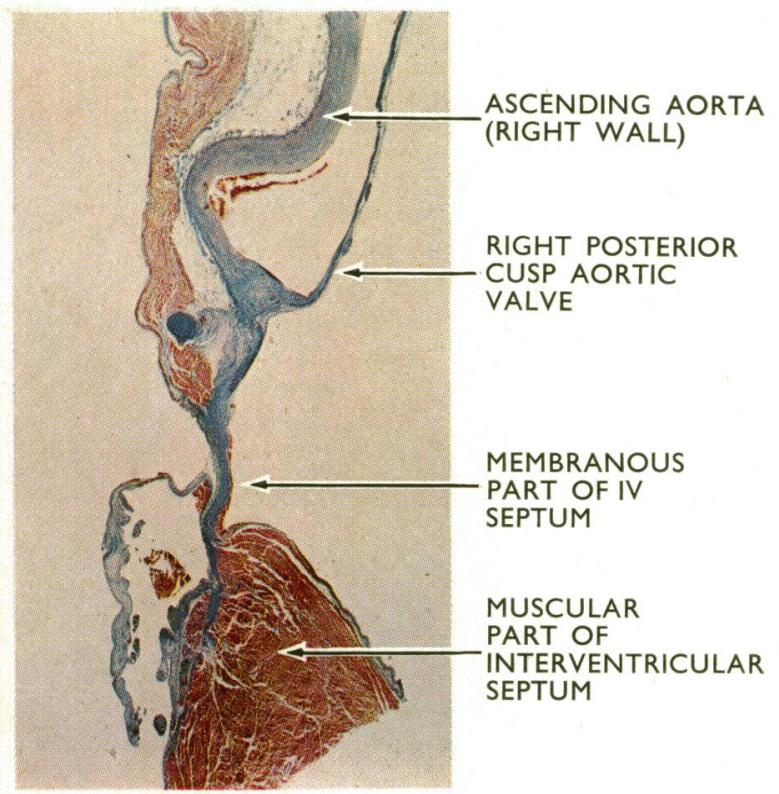

b

Fig. 9a.-A vertical section that passes through the medial wall of right atrium, ascending aorta, and the interventricular septum. The membranous part of the interventricular septum is continuous with the ascending aorta precisely at the site of attachment of the right posterior aortic cusp. The septal cusp of the tricuspid valve in this particular plane is seen to be attached to the endocardium that covers the right side of the muscular part of the interventricular septum. (Masson stain. $\times 3$.)

Fig. 9b.-In this vertical plane of section the septal cusp of the tricuspid valve is attached to the membranous part of the interventricular septum. There are seen to be remnants of numerous chordæ tendineæ passing from the ventricular side of the septal cusp to the interventricular septum. (Masson stain. $\times 3$. )

view of the attachment of the septal cusp of the tricuspid valve to the membranous interventricular septum, it is not surprising that some defects in the membranous portion of the interventricular septum will be of the type described by Buhl (1854), where the left ventricle communicates directly with the right atrium and a left-to-right shunt will be detected at atrial level. Fig. 9b also demonstrates the manner in which a true interventricular defect in the membranous septum may result in a left ventricular to right atrial shunt in those rare cases when there is also a cleft.in the septal cusp of the tricuspid valve through which arterialized blood passes upwards into the right atrium (Gutzeit, 1922). The same figure also explains the variant described by Perry, Burchell, and Edwards in 1949 when they reviewed congenital communications between the left ventricle and right atrium, in which the edges of the split in the septal cusp of the tricuspid valve had become closely adherent to the margins of the defect in the membranous part of the interventricular septum.

An additional important element in the anterior wall of the aortic vestibule is the atrio-ventricular bundle, which, shortly after its origin from the $\mathrm{A}-\mathrm{V}$ node, lies at the junction of the membranous and muscular parts of the interventricular septum (Fig. 10). The bundle is usually separated from the muscular part of the septum by a well-developed mass of fibrous tissue and in its course forwards and upwards along the lower part of the membranous septum divides into its right and left bundles. These conducting pathways are, therefore, exposed to special risks during surgical procedures involving the interventricular septum and the subaortic region.

A feature of the membranous part of the interventricular septum, to which insufficient attention appears to have been given in the past, is the continuity of this part of the septum with the right side of the ascending aorta. This relation of the right wall of the ascending aorta and the membranous interventricular septum can be demonstrated convincingly in coronal sections of the chest, such as those illustrated in Fig. 11 and 12. In these figures the obliquity of the aortic valve is again apparent and its right posterior (non-coronary) 


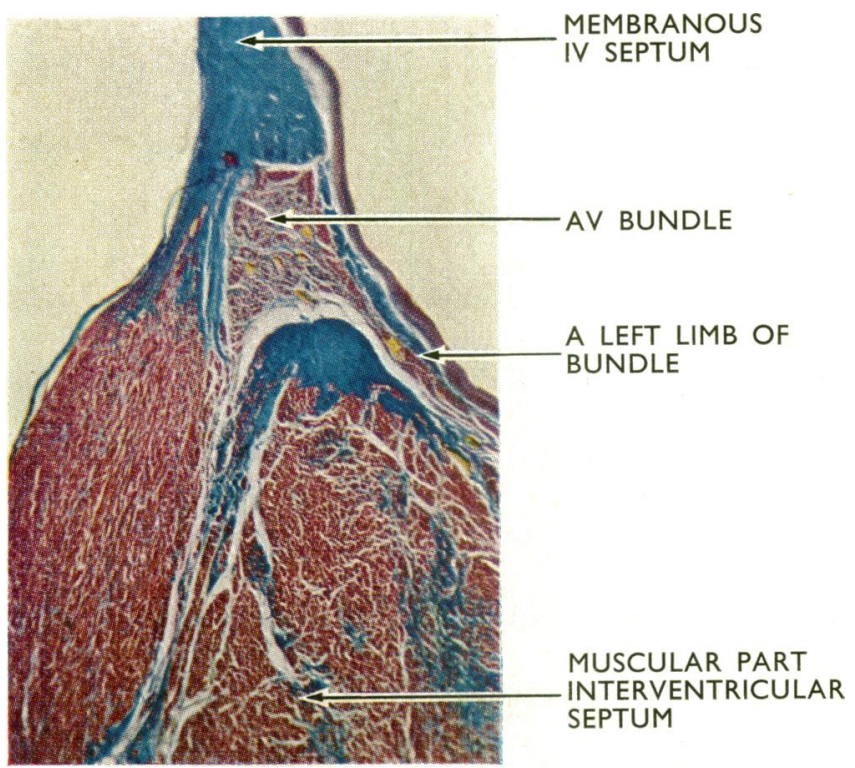

Fig. 10.-This section has been cut in the same plane as those in Fig. 9a and 9b. The greater part of the atrio-ventricular bundle is, however, seen to be interposed between the membranous and the muscular parts of the interventricular septum. A left limb of the bundle passes downwards deep to the endocardium of the left ventricle. Between the main $A-V$ bundle and the muscular part of the septum there is a prominent mass of collagenous tissue, which is stained blue in this section. (Masson stain. $\times 40$.)

cusp is seen to lie at a considerably lower level than the left posterior (left coronary) cusp. In such coronal sections also, it will be noted that whereas the posterior wall of the aortic vestibule is formed by the aortic cusp of the mitral valve, it is the most posterior part of the anterior wall that is partly constituted by the membranous part of the interventricular septum (Fig. 7 and 12).

If transverse sections are made through the aortic vestibule, it is also possible to demonstrate the attachment of the septal cusp of the tricuspid valve to the membranous part of the interventricular septum. As can be seen in Fig. 13, it is this attachment of the septal cusp of the tricuspid valve which determines that the part of the membranous septum that is situated in front and below the cusp is related to the right ventricle, whereas the part that lies behind and above is related to the right atrium. The vestibule of the left ventricular outflow tract as well as the root of the aorta is, therefore, one of the most important relations of the medial wall of the right atrium that is at risk during such procedures as transseptal puncture, and will be described in detail in a subsequent communication (Walmsley and Watson, 1966).

The outflow tracts of the right and left ventricles have a close anatomical relationship to each other. As the terminal part of the right ventricular out- flow tract ascends, it comes to lie increasingly more on the left side of the heart, and in this region the two outflow tracts are separated by the anterior wall of the aortic vestibule, which is constituted mainly by the muscular part of the interventricular septum: though the septum is composed mainly of left ventricular myocardium, it also derives a contribution from the musculature of the right ventricle. As the right ventricular outflow tract ascends to a higher level than the outflow tract of the left heart, the pulmonary valve, therefore, lies at a higher level than the aortic valve, and it is for this reason that the highest part of the infundibulum is related to the commencement of the ascending aorta. As has been previously stated, the right posterior cusp is the lowest of the three cusps of the aortic valve. It is this oblique orientation of the cusps of the aortic valve that determines the multiplicity of close anatomical relationships in the region of the right posterior (non-coronary) cusp of the aortic valve. Sections that pass through the right posterior aortic cusp (and sinus) (Fig. 14) reveal the nearness of the infundibulum and the commencement of the aorta, and the relationship of the right and left atria to each other and to the upper part of the left ventricular outflow tract-the aortic vestibule or subaortic region as this important part of the heart now tends to be called. 


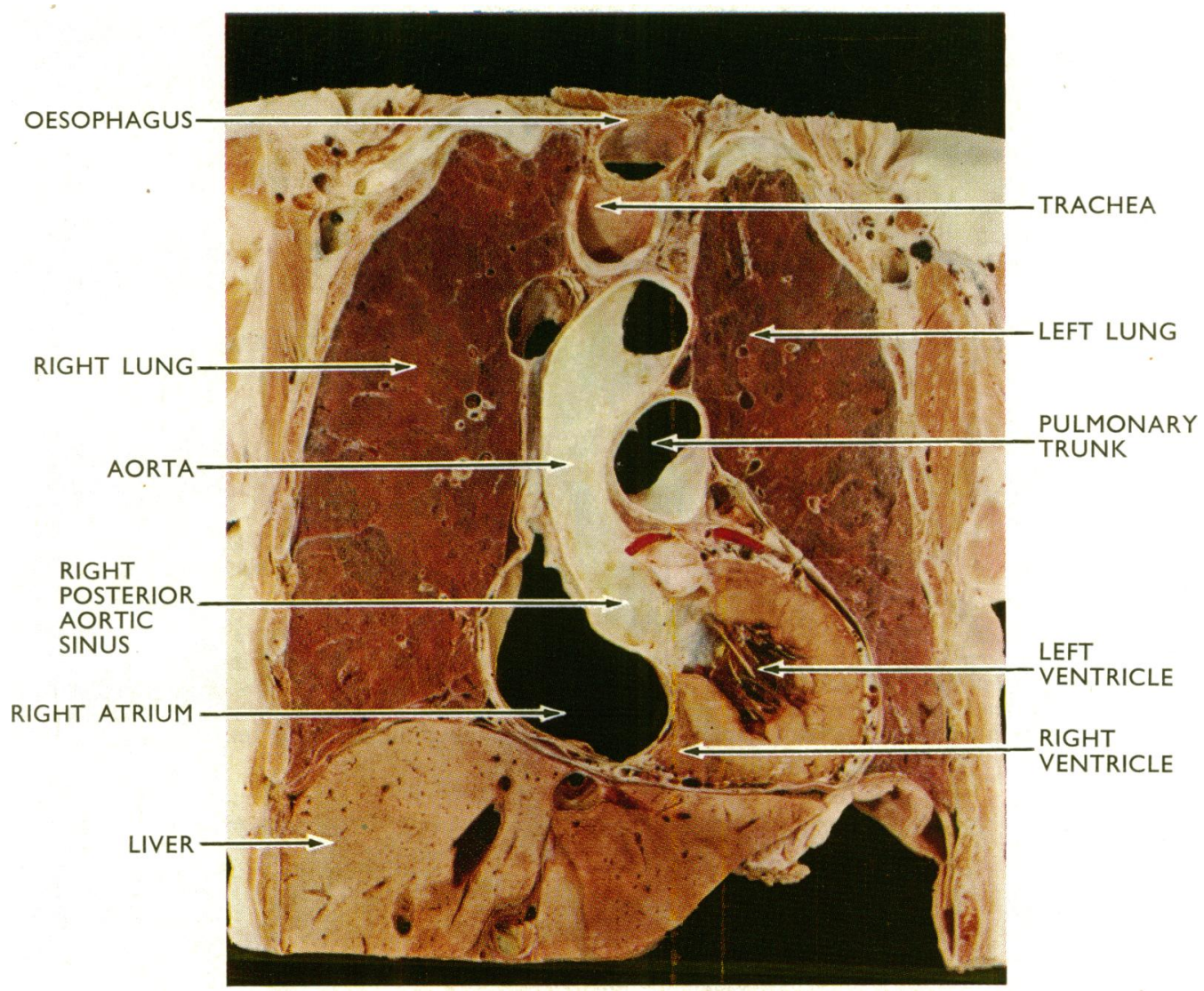

FIG. 11.-Coronal section of adult thorax that shows the ascending aorta arising from the left ventricle. In this plane the right atrium, right ventricle, and left ventricle have all been exposed, but the continuity of the right wall of the ascending aorta with the membranous part of the interventricular septum is more clearly seen in Fig. 12. (Unstained mounted section. $\times 0.45$.)

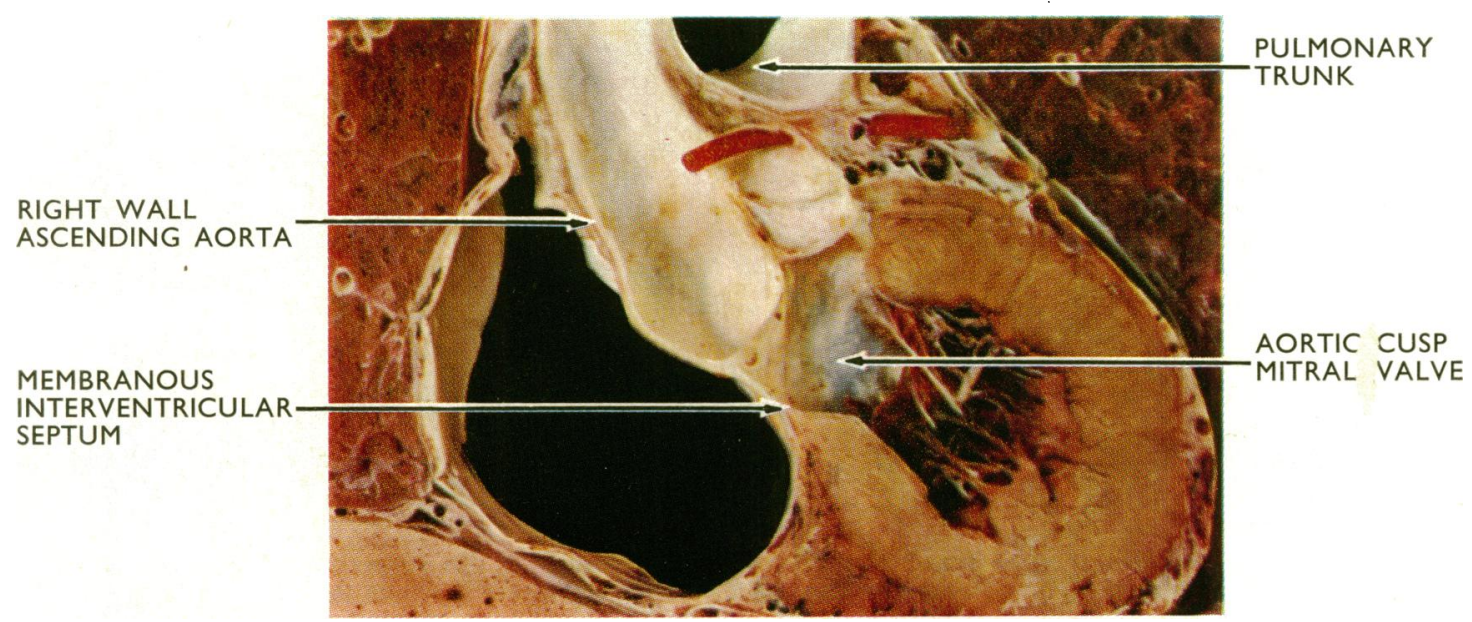

FIG. 12.-This is a higher power view of the region of the root of the ascending aorta and shows more clearly the continuity of the right wall of the aorta with the membranous part of the interventricular septum. A red rod was placed in the left coronary artery and constitutes a guide to the correct orientation of the section. The aortic cusp of the mitral valve forms the posterior wall of the aortic vestibule, and it is seen to have an oblique upper attachment in the region of the bases of the contiguous parts of the right and left posterior aortic cusps. (Unstained mounted section. $\times 0.8$.) 


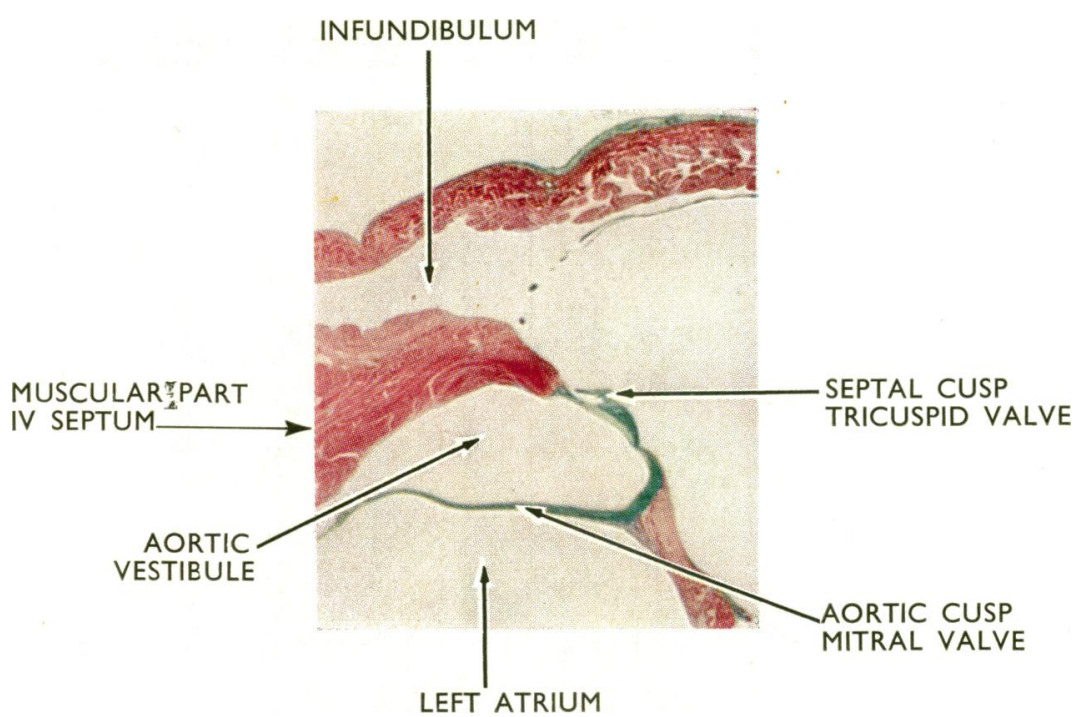

Fig. 13.-Transverse section through an adult heart to illustrate the close relationship of the infundibulum (conus arteriosus) of the right ventricle to the aortic vestibule. Part of the anterior wall of the vestibule is formed by the membranous septum, and the attachment of the septal cusp of the tricuspid valve to this part of the septum is evident. The left atrium is seen to lie posterior to the aortic cusp of the mitral valve. (Masson stain. $\times 1 \cdot 2$.)

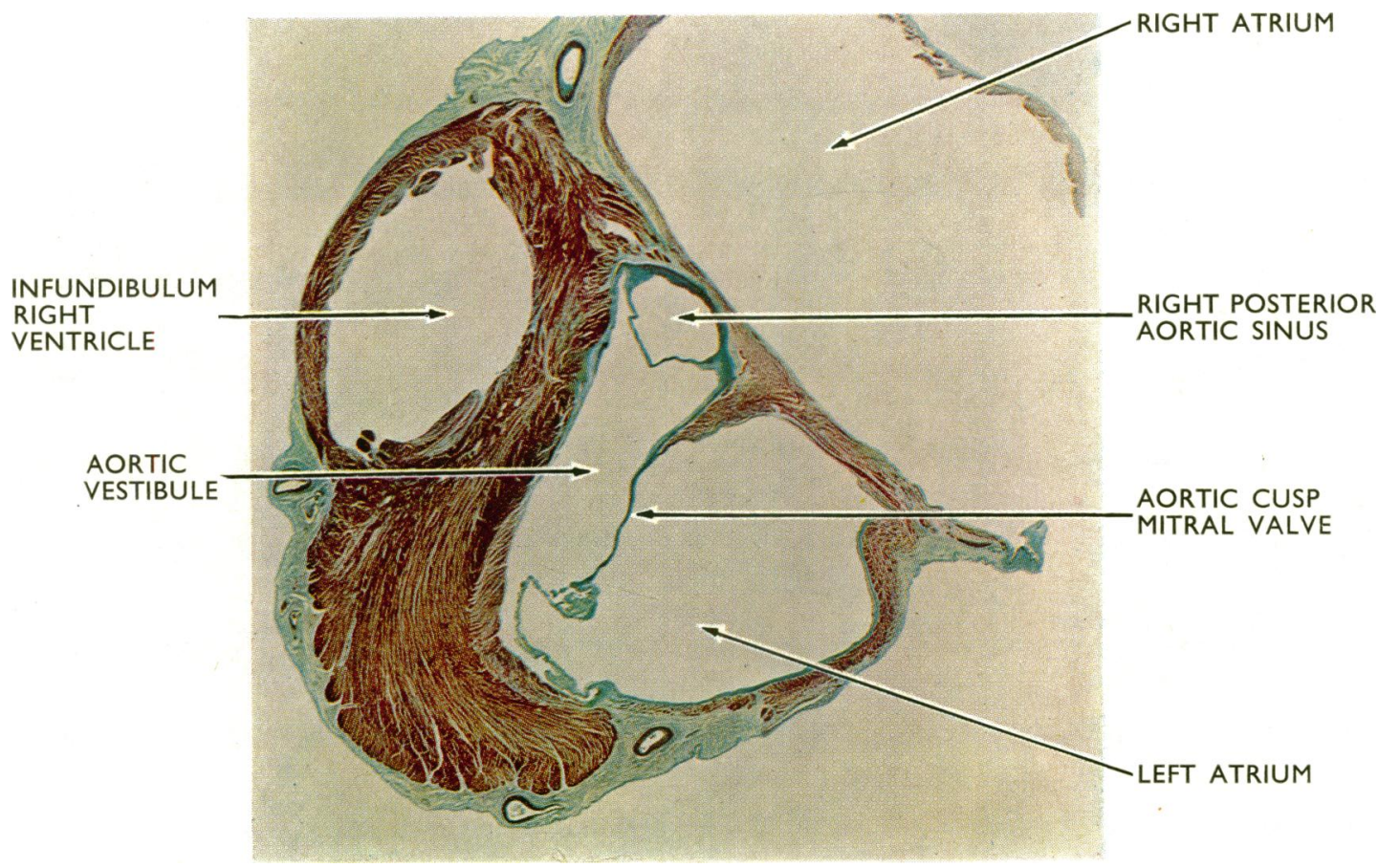

FIG. 14.-Section through upper part of aortic vestibule of adult heart. In this section the right posterior cusp has been transsected, and between this cusp and the commencement of the aorta there lies the right posterior aortic sinus. No evidence is seen of the anterior (right coronary) or the left posterior (left coronary) aortic cusps. The infundibulum (conus arteriosus) at this level lies both in front and to the left side of the aortic vestibule, which is bounded posteriorly by the aortic cusp of the mitral valve. (Masson stain. $\times 1$.) 


\section{SUMMARY}

The anatomy of the left ventricular outflow tract, which extends upwards from the apex of the chamber to the aortic valve, has been described and illustrated. Its upper part is called the aortic vestibule, and its anterior wall is formed by the muscular and membranous parts of the interventricular septum with the atrio-ventricular bundle at their junction. The posterior wall of the vestibule is formed by the aortic cusp of the mitral valve, which divides the chamber into its inflow and outflow portions; it is attached to the cardiac skeleton not only at its base but also at its right and left sides.

The importance of the cardiac skeleton, which is formed by the fusion of the fibrous rings surrounding each valve orifice, has been emphasized, and attention has been focused on the common attachment to it of the aortic cusp of the mitral valve and the adjacent parts of the two posterior cusps of the aortic valve.

The terminal part of the right ventricular outflow tract lies in front and to the left side of the left ventricular outflow tract, and has a close relationship with the aortic vestibule or subaortic region, as this region now tends to be called.

The authors would like to express their appreciation and thanks to the Carnegie Trust for the Universities of Scotland for the generous grant which was made to them to assist in the reproduction of the figures. They also gratefully acknowledge Mrs. E. Ward for Fig. 5, and they thank Mr. R. J. Stuart of St. Salvator's College, St. Andrews, for the considerable technical help he gave throughout the production of this paper.

\section{REFERENCES}

Braunwald, E., Lambrew, C. T., Morrow, A. G., Pierce, G. E.,
Rockoff, S. D., and Ross, J., Jr. (1964). Idiopathic hypertrophic subaortic stenosis. Circulation, 30, Suppl. 4.

-, Morrow, A. G., Cornell, W. P., Aygen, M. M., and Hilbish, T. F. (1960). Idiopathic hypertrophic subaortic stenosis: clinical, hemodynamic and angiographic manifestations. Amer. F. Med., 29, 924.

Brock, R. (1957). Functional obstruction of the left ventricle (acquired aortic subvalvar stenosis). Guy's Hosp. Rep., 106, 221.

Buhl (1854). Communikation der linken Herzkammer mit dem rechten Vorkofe. Z. rationelle Med., n.s. 5, 1. Quoted by Meyer, H. (1857). In Ueber angeborene Enge oder Verschluss der Lungenarterienbahn. Virchow's Arch. path. Anat., 12, 497.

Cunningham's Textbook of Anatomy (1964). 10th edn., ed. G. J. Romanes. Oxford University Press, London.

Gray's Anatomy (1962). 33rd edn., ed. D. V. Davies and F. Davies. Longmans, Green, London.

Gutzeit, K. (1922). Ein Beitrag zur Frage der Herzmissbildungen an Hand eines Falles von kongenitaler Defektbildung im häutigen Ventrikelseptum und von gleichzeitigem Defekt in dem diesem Septumdefekt anliegenden Klappenzipfel der Valvula tricuspidalis. Virchow's Arch. path. Anat., 237, 355.

Kirklin, J. W., and Ellis, F. H. (1961). Surgical relief of diffuse subvalvular aortic stenosis. Circulation, 24, 739.

Luisada, A. A. (1961). (Ed.) Development and Structure of the Cardiovascular System. McGraw-Hill, New York.

Perry, E. L., Burchell, H. B., and Edwards, J. E. (1949). Congenital communications between the left ventricle and the right atrium: co-existing ventricular septal defect and double tricuspid orifice. Proc. Mayo Clin., 24, 198.

Reid, J. (1839). Heart. In The Cyclopaedia of Anatomy and Physiology, ed. R. B. Todd, Vol. 2, p. 577. Longman, Brown, Green, Longmans and Roberts, London.

Walmsley, R., and Watson, H. (1966). The medial wall of the right atrium. (To be published in Circulation.)

Walmsley, T. (1929). Quain's Elements of Anatomy, 11th ed., Vol 4, Part 3: The Heart. Longmans, Green and Co., London. 